\title{
Sect, Nation, and Identity after the Fall of Mosul: Evidence from a Natural Experiment
}

\author{
Christopher Barrie \\ November 29, 2019 \\ Latest version under review
}

\begin{abstract}
How does war affect group identity? Does common threat unite ethnic groups behind the nation? What explains subethnic heterogeneity in identity responses? Experimental scholarship on conflict and intergroup identity relies on laboratory settings; identifying real-world variation is hindered by the difficulties of conducting social inquiry in wartime. I address this gap by exploiting a unique source of exogenous variation - the fall of Mosul to the Islamic State of Iraq and al-Sham-during the fieldwork for a nationally representative survey in Iraq. I find systematic differences in the identity responses of Sunni and Shi'i Iraqis. While Shi'is cleave to the nation, Sunnis mobilize behind an Arab identity. In tribal areas, however, Sunnis rally behind the nation. Findings are explained with reference to prior attachment and achieved cooperation. Excluded groups are less likely to identify with the nation; but where organization enables interethnic cooperation, wartime mobilization generates national loyalty.
\end{abstract}

